\title{
Opportunistic infections among individuals with HIV-1/ AIDS in the highly active antiretroviral therapy era at a Quaternary Level Care Teaching Hospital
}

\author{
Katia Jaira Galisteu ${ }^{[1]}$, Luciana Ventura Cardoso ${ }^{[1]}$, Adriana Antônia da Cruz Furini ${ }^{[1],[2],}$ \\ Arlindo Schiesari Júnior ${ }^{[3]}$, Claudia Bernardi Cesarino ${ }^{[1]}$, Célia Franco ${ }^{[4]}$, \\ Andrea Regina de Souza Baptista ${ }^{[5]}$ and Ricardo Luiz Dantas Machado ${ }^{[6]}$
}

[1]. Centro de Investigação de Microrganismos, Faculdade de Medicina de São José do Rio Preto, São José do Rio Preto, São Paulo, Brasil. [2]. Centro Universitário de Rio Preto, São José do Rio Preto, São Paulo, Brasil. [3]. Faculdade Integradas Padre Albino, Catanduva, São Paulo, Brasil. [4]. Hospital de Base, São José do Rio Preto, São Paulo, Brasil. [5]. Departamento de Microbiologia e Parasitologia, Universidade Federal Fluminense, Niterói, Rio de Janeiro, Brasil. [6]. Seção de Parasitologia, Instituto Evandro Chagas, Ananindeua, Pará, Brasil.

\begin{abstract}
Introduction: In this study, clinical-laboratory and epidemiological characteristics are described for a group of 700 individuals with HIV (human immunodeficiency virus)/AIDS (acquired immunodeficiency syndrome) in the ART (antiretroviral therapy) era at a teaching hospital that provides a quaternary level of care, with an emphasis on opportunistic infections (OIs), co-infections and immune profile. Methods: A retrospective cross-sectional study of AIDS cases was conducted from 1998 to 2008 by reviewing medical records from the Base Hospital/FUNFARME (Fundação Faculdade Regional de Medicina), São José do Rio Preto, São Paulo, Brazil. Results: The individuals were 14 to 75 years of age, and 458 were males. Heterosexuals accounted for $31.1 \%$ of all patients. Eighty-three percent were on ART, and 33.8\% of those presented difficulties with treatment adherence. OIs were analyzed from medical records, and Pneumocystis jiroveci pneumonia was the most prevalent, regardless of the LTCD4 ${ }^{+}$TCD4 $^{+}$Lymphocytes) levels. Individuals whose viral loads were $\geq 10,000$ showed a $90 \%$ greater chance of neurotoxoplasmosis. For $P$. jiroveci pneumonia, neurotoxoplasmosis, esophageal candidiasis, pulmonary tuberculosis and neurocryptococcosis, the chances of infection were higher among patients with LTCD4 ${ }^{+}$levels below 200 cells $/ \mathrm{mm}^{3}$. HIV/ hepatitis $\mathrm{C}$ virus (HCV) and $\mathrm{HIV} /$ hepatitis B virus (HBV) co-infections were significantly associated with death. Conclusions: OIs remain frequent in the ART era even in populations where the access to medical care is considered satisfactory.
\end{abstract}

Keywords: HBV. HCV. HIV. Opportunistic infections.

\section{INTRODUCTION}

Three decades after the discovery of the human immunodeficiency virus (HIV), it is estimated that 33.4 million people worldwide are living with the virus. In Brazil, 608,230 cases of AIDS were reported from 1980 to June 2011, and 186,445 of these cases were reported in the State of São Paulo. In 2012, the observed frequency of the disease in São José do Rio Preto, a city located in the Northwest region of São Paulo, was $33.2 / 100,000^{(1)}$. The virus can be spread to individuals of all social levels. In Brazil, social, economic and cultural inequalities favor the spread of AIDS, with impoverishment of the infected population. Other characteristics of the epidemic

Corresponding author: Prof. Ricardo Luiz Dantas Machado. Seção de Parasitologia/IEC/SVS/MS. BR 316, Km 7, s/n, Levilândia, 67030-000 Ananindeua, Pará, Brasil.

Phone: 559132142382

e-mail: ricardomachado@iec.pa.gov.br

Received 5 December 2014

Accepted 26 March 2015 are an increased number of cases among individuals who have sex with someone of the opposite gender, feminization, aging and an increased number of infected individuals outside major urban centers, a process also known as interiorization ${ }^{(1)(2)(3)}$. In Brazil, AIDS is an epidemic with a wide spectrum of clinical presentations and without a single epidemiological profile, is concentrated in high risk and vulnerable populations, and has regional subepidemics ${ }^{(1)}$.

Antiretroviral therapy (ART) has been available since 1996 for individuals diagnosed with AIDS and has allowed long-term control of the disease with increased survival ${ }^{(4)(5)}$ and decreased morbidity and mortality rates ${ }^{(5)}$. However, AIDS has become a chronic and degenerative disease for patients undergoing $\mathrm{ART}^{(1)(2)(6)}$. In 2012, 313,000 individuals were on ART in Brazil ${ }^{(1)}$, and $76 \%$ of these patients had an undetectable viral load ${ }^{(1)}$.

The advances in the arsenal of antiretroviral therapy have reduced the HIV viral load, the occurrence of opportunistic infections (OIs), and death rates due to AIDS, especially in patients with increased CD4+ T cell counts ${ }^{(4)(5)(6)(7)}$. However, even in the ART era, HIV-related OIs are still an important cause of hospitalization and death ${ }^{(3)(5)(7)(8)}$, which may be the 
result of late diagnosis and low levels of CD4+ T cell counts ${ }^{(8)}$. According to the Centers for Disease Control and Prevention (CDC) classification ${ }^{(9)}$, several diseases are considered OIs for HIV-seropositive patients. In tropical regions, HIV infection is associated with high prevalences of tuberculosis, neurotoxoplasmosis, chronic diarrhea and lung diseases ${ }^{(1)(9)}$. However, the variability of host-etiological agent interactions and difficulties in the diagnosis of some OIs contribute to a lack of data that demonstrate consistent evidence of the effects of $\mathrm{OIs}^{(7)(10)}$.

Based on the epidemiological diversity observed in different regions of Brazil, studies about AIDS are very important and contribute to the creation of regional public health policies that include strategies targeted to the particular needs of HIVpositive populations and corresponding health services. In this study, clinical-laboratory and epidemiological characteristics are described in a sample of 700 individuals with HIV/AIDS in the ART era in a teaching hospital that provides a quaternary level of care, with an emphasis on OIs, confections and immune profiles.

\section{METHODS}

This investigation was a cross-sectional study with data obtained from January 1998 to December 2008. During this period, medical records from 1972 living patients and 979 deceased patients were available. The sample size studied represented $23 \%$ of the patients. In total, 700 patients with a diagnosis of HIV/AIDS were evaluated. Five hundred medical records were from living patients, and 200 were from deceased patients. These data are part of the archive of the Infectious and Parasitic Diseases Outpatient Clinic at the Base Hospital/ Regional Medical School Foundation [Ambulatório de Doenças Infecciosas e Parasitárias do Hospital de Base (ADIPHB), Fundação Faculdade Regional de Medicina (FUNFARME)], São José do Rio Preto, São Paulo, Brazil. The Base Hospital $(\mathrm{BH})$ is a large quaternary level care teaching hospital (720 beds) that provides specialized care. It is an important reference hospital for health care services in the Northwest region of the State of São Paulo and is linked to the Medical School and Nursing School programs of the São José do Rio Preto Medical School [Faculdade de Medicina de São José do Rio Preto (FAMERP)]. The City of São José do Rio Preto has approximately 408,435 inhabitants $^{(11)}$ and is located $454 \mathrm{~km}$ from the City of São Paulo.

This study was approved by the Research Ethics Committee of the São José do Rio Preto Medical School/FAMERP under protocol no 3361/2008 and was conducted in accordance with the required ethical standards. The inclusion criteria of the study were individuals older than 13 years who were diagnosed with HIV-1/AIDS and on ART. The exclusion criteria were cases where the medical records did not have at least $80 \%$ of the information requested by the instrument. Data collection from the medical records (both paper and electronic formats) was performed using a protocol standardized by physicians specializing in infectious diseases, nurses, pharmacists and other health care professionals involved in the study.
The data analyzed included age, gender, educational level, area of residence (rural or urban), date of diagnosis of HIV-1 infection, categories of exposure to HIV-1 acquisition, identification and frequency of AIDS-defining $\mathrm{OIs}^{(6)}{ }^{(9)}$, serum CD4+ T cell counts and HIV viral load levels at the diagnosis of the OI. In addition, information in the medical records about the use of ART and patient adherence to treatment (assessed by the receipt of antiretroviral drugs from the pharmacy) were evaluated. The presence of co-infections with hepatitis B virus (HBV) and hepatitis $\mathrm{C}$ virus (HCV) were also investigated. This study considered AIDS-defining OIs as those OIs that met the CDC criteria adapted by the Brazilian Ministry of Health. Statistical analyses were performed using R software, version 2.4.1 (The R Foundation for Statistical Computing ISBN 3-900051-070 - http://www.r-project.org, Vienna, Austria). Fisher's exact test was used to analyze independence among the proportions. The proportion and probability (odds ratio) were adjusted, and $95 \%$ confidence intervals were estimated. The level of significance adopted for statistical inference was $5 \%$; p-value $<0.05$ was considered statistically significant.

\section{RESULTS}

The ages of the analyzed patients (700 cases) ranged from 14 to 75 years, with a mean age of 41.8 years. Of these patients, $458(65.4 \%)$ were males. An educational level of less than eight years of education was observed in $51.6 \%(\mathrm{n}=361)$ of the cases, and $91.4 \%(n=640)$ of the individuals resided in urban areas. HIV was diagnosed during hospitalization or medical treatment of other diseases in 317 (45.3\%) patients. Thirty $(\mathrm{n}=211)$ percent of the individuals were previously diagnosed with HIV-1 (Table 1). Regarding the categories of exposure to HIV-1, 31.1\% of the individuals were heterosexual. However, this information was not available in $48.1 \%$ of the medical records analyzed in this study (Table 1).

Among the outpatients, $83 \%$ were on ART, and problems with treatment adherence were reported in $33.8 \%$ of these cases. OIs were observed in 297 individuals, representing $42.5 \%$ of the patients, and patients with more than one OI were observed. Table 2 shows the most prevalent OIs observed in patients on ART according to the LTCD4 ${ }^{+}$levels and viral load. Pneumocystis jiroveci pneumonia was the most prevalent OI, regardless of the $\mathrm{LTCD}^{+}$levels or viral load, with $17.7 \%$ (p-value $<0.01$ ) greater than 200 cells $/ \mathrm{mm}^{3}$ and $28 \%$ below 200 cells $/ \mathrm{mm}^{3}$. This OI had a $55 \%$ lower chance $(0.37-0.83)$ of affecting patients with levels of LTCD4 $4^{+}$greater than 200 cells $/ \mathrm{mm}^{3}$. However, no association with viral loads was found. The second most prevalent OI was neurotoxoplasmosis, presenting a 0.3 times (0.18-0.49) lower chance of occurrence in patients whose LTCD $4^{+}$levels were high ( $p$-value $<0.01$ ). Neurotoxoplasmosis preferably affected individuals whose viral loads were $\geq 10,000$ ( $p$-value $<0.01$ ), who presented $90 \%(1.11-3.24)$ greater chances of developing this OI than those with viral loads below this count. Esophageal candidiasis, pulmonary tuberculosis and neurocryptococcosis also had lower chances of afflicting patients whose LTCD $4^{+}$levels were above 200 cells $/ \mathrm{mm}^{3}$ ( $p$-value $\leq 0.01$ ). 
TABLE 1 - Demographic, diagnostic and exposure to HIV variables in 700 patients treated at Base Hospital/FUNFARME of São José do Rio Preto, State of São Paulo, Brazil.

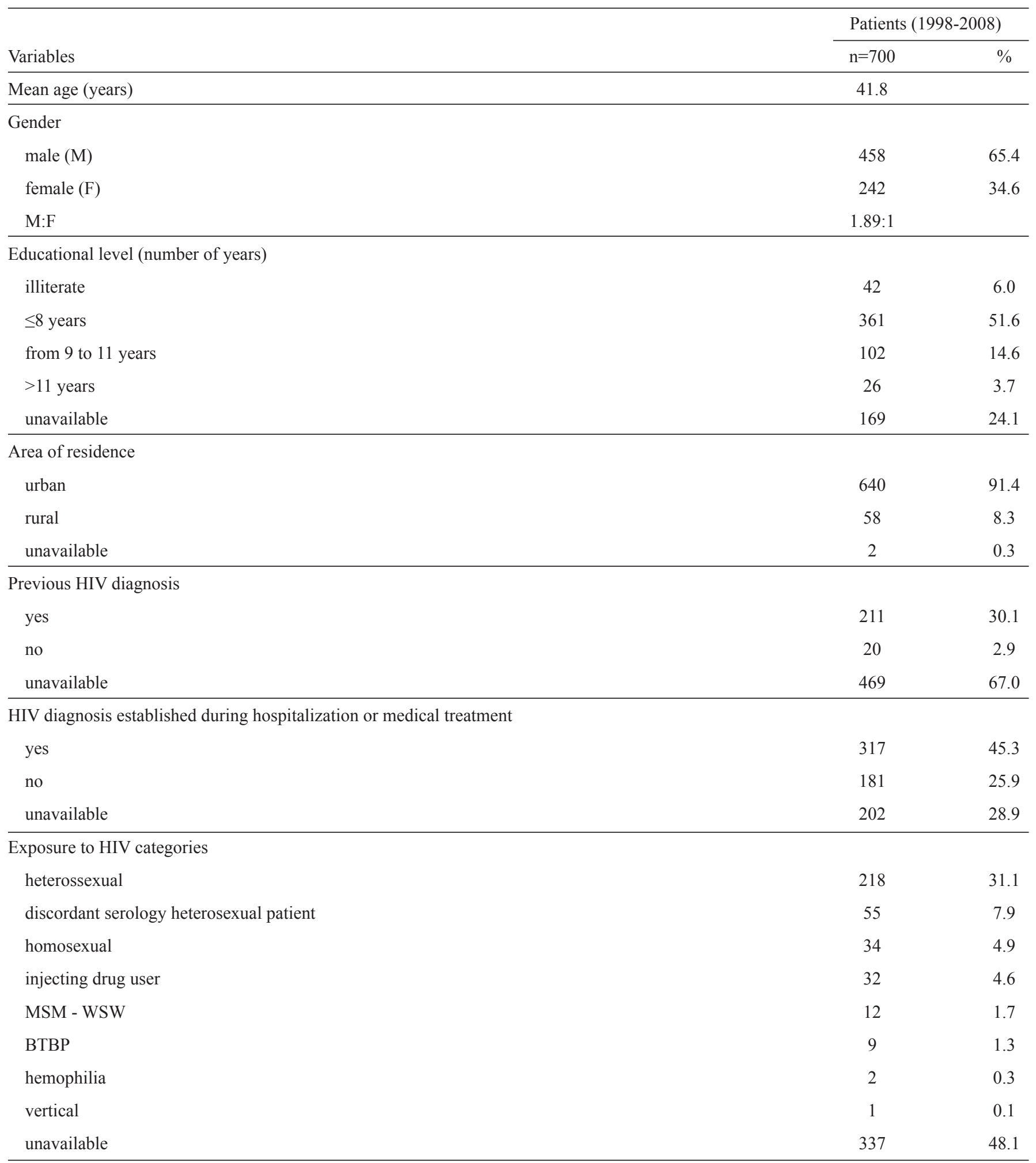

HIV: human immunodeficiency virus; FUNFARME: Fundação Faculdade Regional de Medicina; MSM: men who have sex with men; WSW: women who have sex with men and women; BTBP: blood transfusion and blood products. 
Tuberculosis was the most prevalent OI among the deceased patients, with $23.5 \%$ (p-value $<0.01$ ) and 2.15 times $(1.45-3.18)$ greater chances of occurrence in this group. Cryptococcosis (p-value $<0.01)$ was also associated with a $2.12(1.27-3.58)$ times greater chance of a death outcome. Patients whose deaths were not due to OI were not evaluated in this study. For 57/200 death cases investigated, the survival time was, on average, one year and seven months after the diagnosis of HIV-1.

Table 3 presents the frequencies of patients with HIV/ HBV or HIV/HCV co-infection. HIV-1/HCV (p-value $<0.01$ ) and HIV/HBV (p-value $<0.01$ ) co-infections were significantly associated with death in patients on ART.

\section{DISCUSSION}

In 2011 in Brazil, HIV was more prevalent in both males and females aged 30 to 44 years old ${ }^{(1)}$. The present study revealed a higher incidence of HIV among young adult males, as previously described by our group at the municipality of Catanduva, São Paulo $^{(2)}$. However, there was a decrease in the male: female (M:F) ratio among infected individuals in the ART era (1.89M:1F), which is in agreement with the current trend of the spread of the HIV/AIDS epidemic among women ${ }^{(12)}$. This ratio was $4.5 \mathrm{M}: 1 \mathrm{~F}$ in São José do Rio Preto in the 1980s and 1990s. In 2009, with the drop in the number of infected men, this ratio was $2 \mathrm{M}: 1 \mathrm{~F}$, which is similar to the national average observed in $2011(1.7 \mathrm{M}: 1 \mathrm{~F})^{(1)(13)}$.

The increased number of cases among heterosexuals is a critical factor favoring the increased number of HIV infections among females. These data reveal the importance of interrupting the epidemiological chain that is underway in our region ${ }^{(2)}$ through preventive policies that focus on the contribution of females to the epidemic. It is undeniable that the present study illustrates a regional profile of the epidemic's course; however, further studies involving all reported AIDS cases and not only outpatients are still needed to obtain a clearer profile of the current extent of the phenomenon. In addition, cultural factors can be an additional risk for the increased number of cases among women, especially in the men having sex with women (MSW) group, who do not demand the use of condoms most of the time.

Homosexuals/bisexuals represent $6.6 \%$ of the patients analyzed, and heterosexuals represent $31.1 \%$. In the United States, the transmission of HIV among men who have sex with men represented $78 \%$ of cases among men aged 13 to 24 years of age $^{(14)}$. In the Brazilian population, the most significant increase in HIV-positive cases was observed among young individuals belonging to the MSM group, whose frequency increased from $0.56 \%$ in 2002 to $1.2 \%$ in $2007^{(1)}$. Information regarding sexuality is typically rare, which may result from bisexual behavior being hidden due to cultural issues, leading this group to declare themselves as heterosexuals ${ }^{(2)(14)(15)}$. Prophylactic intervention is very important in this group, and experimental models have demonstrated that it can reduce the risk of HIV transmission in the MSM group by $25 \%$. Diagnostic intervention is recommended at least once a year in this group and every 3-6 months in MSM/injection drug users ${ }^{(14)(15)}$. 
TABLE 3 - Presence of HIV/HCV, HIV/HBV co-infection in the ART era in patients treated at the Base Hospital/FUNFARME of São José do Rio Preto, State of São Paulo, Brazil.

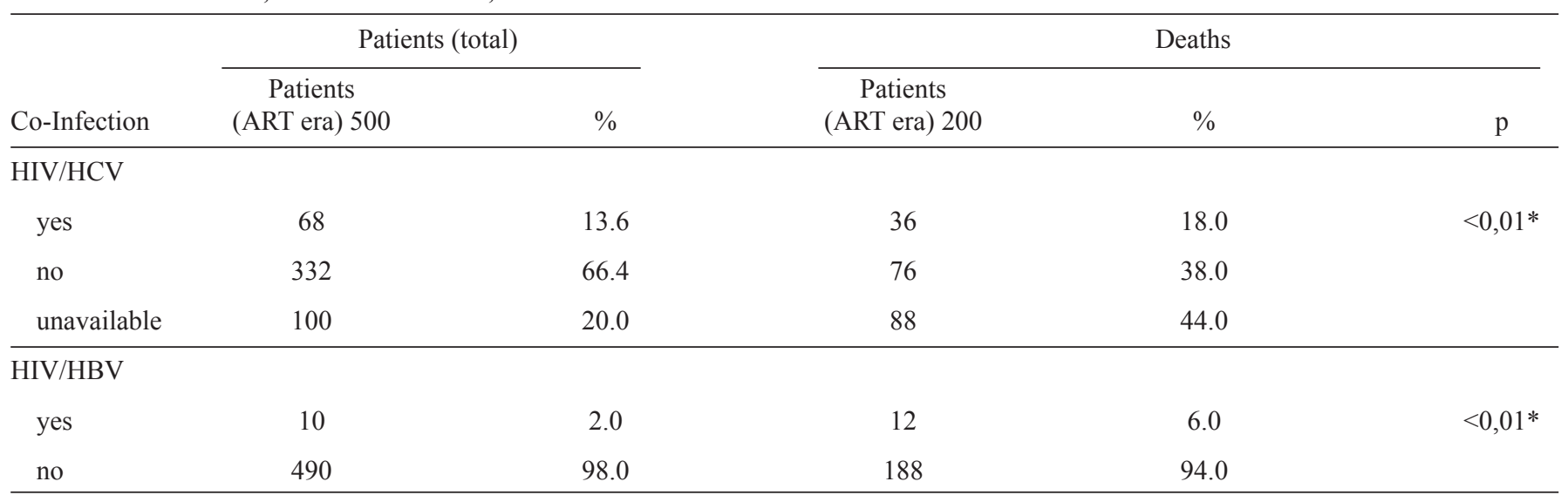

HIV: human immunodeficiency virus; HCV: hepatitis C virus; HBV: hepatitis B virus; ART: antiretroviral therapy; FUNFARME: Fundação Faculdade Regional de Medicina; *Fisher's test, p values for occasion of death.

Human immunodeficiency virus transmission through injection drug use (IDU) was common in the period before ART; however, the results obtained in the present study showed a significant decrease in IDU in the ART era (4.6\%). The municipality of São José do Rio Preto was an important drug trafficking route until 1992, and therefore, the use of injectable drugs and MSM behavior were the main forms of HIV-1 transmission. Starting in 1994, heterosexuals became the predominant category of exposure to HIV, which is still observed today, with men and especially women in stable relationships being affected ${ }^{(13)}$. In fact, among the 13,447 HIV-positive cases with classification of exposure reported in the Notifiable Diseases Information System [Sistema de Informação de Agravos de Notificação (SINAN)], 52.7\% were heterosexual ${ }^{(1)}$ and therefore critical for expansion of the epidemic among women.

Individuals with low educational levels have been most affected by the disease in Brazil ${ }^{(1)(15)(16)}$. Our data reveal an association between HIV-infected individuals in the ART era and low (51.6\%) educational level. The impoverishment of the epidemic observed in our study is similar to the scenario reported in a study conducted in the City of São Paulo that demonstrated that low educational levels (less than eight years of education) and poor professional skills are predisposing factors to HIV infection and treatment noncompliance (2) (15) (16). Additionally, a study conducted in the City of São Paulo with 1,837 HIV-seropositive individuals revealed that $76.3 \%$ had only a primary education. Recent studies indicate impoverishment among the infected population ${ }^{(15)}$. These data contrast with the epidemiological profile observed at the beginning of the epidemic, where the majority of the patients had high school education or college degrees ${ }^{(16)(17)}$. However, it should be emphasized that few individuals with higher levels of education were treated at the ADIPHB service, most likely because this is a public regional reference center for infectious and parasitic diseases.

Another trend characterizing the epidemic is that in addition to the major urban centers, the disease is also spreading to smaller towns (interiorization) and rural areas (ruralization). This result was also found by our group in a hospital in the City of Catanduva, located in a rural area of the State of São Paulo ${ }^{(2)}$. The growth of the epidemic in rural areas is reported in the Brazilian literature ${ }^{(18)}$. Although the present study demonstrated that only $8.3 \%$ of patients live in rural areas, this fact should not be underestimated in the region. This low rate of seropositive patients living in rural areas may be due to cultural and economic aspects or to their limited access to specialized health care services.

Only $30 \%$ of the patients were tested for HIV-1 before seeking care at the health care service. The current municipal health care policy recommends decentralized diagnostic testing for HIV-1, i.e., individuals should undergo rapid diagnostic testing at units that provide primary health care, and if necessary, they should be referred to a specialized service to confirm the diagnosis and for clinical follow-up ${ }^{(13)}$. Accordingly, our results are worrisome because the primary health care units are not performing diagnoses, and the diagnosis is typically established as a result of OIs or co-infections that can affect seropositive individuals. In addition, a delayed diagnosis may occur due to fear of a positive result and prejudice that make people avoid HIV serologic tests. When the diagnosis is postponed, a continuous cycle of transmission and lack of access to therapeutic measures ensues.

Adherence to treatment is a determining factor in improving the quality of life of patients and the treatment success; however, it is one of the biggest challenges for AIDS patients ${ }^{(19)}$. For ART to be effective, i.e., undetectable plasma viral loads are achieved at least $95 \%$ of the daily doses must be taken. In the present study, treatment adherence was measured by pharmacy records, which indicated that $33.8 \%$ of patients displayed some degree of non-adherence. Treatment adherence depends on changes in patient behavior, diet, and awareness of polytherapy use for the rest of their lives. Measures such as providing information and guidance as well as psychological counseling should 
be undertaken at the health care unit under study to reduce treatment non-adherence. Another proposal that should be considered is the offer of specific activities focused on treatment adherence, care provided by the entire multidisciplinary team, and individualized pharmaceutical care with discussion about drug and food interactions and adverse drug reactions ${ }^{(19)}$. A bias of this analysis was the fact that the effects of socio-demographic factors, health care service, and vulnerability to HIV, which may be associated with non-adherence to treatment, were not evaluated.

Diseases caused by fungi are important causes of morbidity among AIDS patients and frequent OIs among HIV-1 positive individuals ${ }^{(20)}$ and can affect up to $94 \%$ of infected individuals, depending on the stage of the infection and the population analyzed ${ }^{(7)}$. Candidiasis was the most common infection observed before the use of $\mathrm{ART}^{(8)}$. Esophageal candidiasis was reported in the medical records of $10.2 \%$ of all patients whose LTCD4+ levels were below 200 cells $/ \mathrm{mm}^{3}$ and $8.6 \%$ of those with viral loads $\geq 10,000$ copies $/ \mathrm{mL}$. The incidence of this disease in the ART era was $22 \%$ in the municipality of Catanduva, and it was the most frequent $\mathrm{OI}^{(2)}$. The low incidence of candidiasis observed in the present study may be a consequence of the types of candidiasis not being correctly specified in the medical records and the CDC criteria being followed, which classify only esophageal candidiasis as an $\mathrm{OI}^{(9)}$. Increased viral load contributed to the greater susceptibility to the development of esophageal candidiasis, even in patients who are on antiretroviral therapy, which should result in a lower incidence of OIs. The incidence of OIs in patients may also be due to immune reconstitution syndrome ${ }^{(21)}$. Among the systemic mycoses, cryptococcosis is the most frequently observed in AIDS patients, especially in the form of meningoencephalitis. Its worldwide prevalence varies from $2.9 \%$ to $13.3 \%$, and it is a significant cause of mortality in AIDS. In the present study, this fungal disease was detected in $8.4 \%$ of all patients with LTCD4+ levels below 200 cells $/ \mathrm{mm}^{3}$ and viral loads $\geq 10,000$ copies $/ \mathrm{mL}$. A similar prevalence of cryptococcosis is observed in European countries (6\% to $13 \%$ of AIDS patients) ${ }^{(22)}$.

Pulmonary diseases are common and serious complications ${ }^{(23)}$ and the main cause of morbidity and mortality among individuals infected with HIV-1(9) (23) (24). Despite regional differences, $P$. jiroveci pneumonia is the most frequent OI among HIV-seropositive individuals and is the most common clinical manifestation $^{(7)}{ }^{(9)}$. However, an association between pneumonia-causing agents and death was not found in the population studied, most likely because information about the pneumonia causative agent was not available in most of the medical records.

HIV infection is considered one of the main risk factors for tuberculosis (TB) and mycobacteriosis. TB is the main cause of morbidity and mortality among HIV-seropositive individuals at a rate of one-third of deaths among AIDS patients. Immunological suppression caused by HIV increases the risk of latent TB infection progress to active $\mathrm{TB}^{(24)(25)(26)}$. According to the World Health Organization, 8.8 to 9.2 million TB cases were reported in 2010, and 1.2 million of these cases were TB/HIV co-infections, which represents a challenge for public health programs. The present study found a low incidence of tuberculosis, but with a significant association between HIV-1/TB co-infection and death (23.5\% of cases). The fact that HIV-1/TB co-infection was found in $23.5 \%$ of patients who died at the $\mathrm{BH}$ in the ART era suggests a late and/ or erroneous clinical diagnosis of this co-infection ${ }^{(18)}$, and the lack of investigations for TB in these patients. In 2004, only $40 \%$ of TB patients were screened for HIV, and in 2007, this rate increased to $80 \%{ }^{(25)}$. However, laboratory diagnoses of Mycobacterium spp. in HIV/AIDS patients through bacilloscopy and culture phenotypic methods typically have low sensitivity due to the paucibacillary character (except in cavitations) of the disease in these individuals ${ }^{(24)}$. In the Brazilian Public Health Care System, TB diagnosis is typically based on bacilloscopy, and culture and biochemical tests for Mycobacterium spp. are recommended only in cases of suspicion of pulmonary TB with negative bacilloscopy. However, culture tests are available for HIV-seropositive patients ${ }^{(26)}$.

Data from the World Health Organization (WHO) indicate that more than 180 million people are chronically infected with $\mathrm{HCV}$, and 7 million are co-infected with $\mathrm{HIV}^{(27)}$. In Brazil, the incidence of $\mathrm{HIV} / \mathrm{HCV}$ co-infection varies according to geographical distribution and risk factors for disease acquisition, such as age, gender and type of exposure, and ranges from $17 \%$ to $53 \%{ }^{(27)(28)(29)}$. The similarity in the routes of transmission, such as sexual, vertical and parenteral (including the use of injectable drugs), associates HIV with several forms of hepatitis, especially those caused by $\mathrm{HCV}^{(1)(27)(29)}$. Hepatitis is an important cause of morbidity and mortality among HIV-seropositive patients ${ }^{(29)}$. The incidence of HIV/HCV co-infection observed in the present study is similar to that reported in the literature. However, the incidence of HIV-1/HBV co-infection was low in the population studied (2\% in living patients and $6 \%$ in deceased patients) and similar to the rate observed in the Western Brazilian Amazon $(6.4 \%)^{(29)}$. In contrast, a study conducted in New Mexico, United States, showed high rates of positivity for these two coinfections $(82.2 \% \text { and } 61.1 \% \text {, respectively })^{(30)}$. It is known that the incidence of HCV infection varies according to geographical area, risk behavior and laboratory methods for virus detection ${ }^{(27)}$. In addition, $\mathrm{HIV} / \mathrm{HCV}$ and $\mathrm{HIV} / \mathrm{HBV}$ co-infections were significantly associated with progression to death in the ART era (p-value $<0.01$ and $\mathrm{p}$-value $<0.01$, respectively). ART and hepatitis therapy can cause severe hepatotoxicity and therefore contribute to morbidity and mortality. In fact, HIV/ HBV co-infected patients presented 5-6 times greater chances of progression to chronicity, reactivation and liver cancer. The $\mathrm{HIV} / \mathrm{HCV}$ co-infected patients can progress with liver failure and cirrhosis $^{(31)}$. Surveys and knowledge about HIV/HCV co-infection are essential for public health agencies to devise strategies to control and prevent HIV and HCV infections. Unfortunately, the lack of some information in the records analyzed, especially related to genotyping and HCV treatment, restricted a deeper analysis of the topic in question because the treatment for hepatitis $\mathrm{C}$ in co-infected patients represented a major goal of this study, i.e., to assess HCV infection in HIVinfected patients. Surveys and knowledge about HIV/HCV 
co-infections are essential for public health agencies to devise strategies to control and prevent HIV and HCV infections. In addition, understanding the factors associated with host-virus interaction from a molecular perspective is important for $\mathrm{HCV}$ treatment. The emergence of new strategies to achieve a more effective treatment, as well as monitoring patients with chronic $\mathrm{HCV}$ infection and co-infection with HIV, in the coming years may help reduce the number of infected patients.

In conclusion, OIs remain frequent in the ART era even in populations where access to medical care is considered satisfactory. Our findings demonstrated that these diseases can arise with any level of viral load and CD4+ T cell count. The low educational level described may explain the non-adherence to ART and/or prophylaxis for opportunistic diseases. While the cases reported here are representative of the community infected by HIV-1 in the northwest region of the State of São Paulo, the data can be used for future comparisons at different levels, such as institutional, inter-institutional, regional and other developing countries. Finally, the extensive qualifications of health care professionals indicate early diagnosis and appropriate treatment of AIDS as important measures for the survival of patients suffering from this condition. The effect of confounding factors, especially incomplete medical records, is a limitation of retrospective studies.

\section{CONFLICT OF INTEREST}

The authors declare that there is no conflict of interest.

\section{FINANCIAL SUPPORT}

This study was funded by the São José do Rio Preto Medical School and by the São José do Rio Preto Base Hospital.

\section{REFERENCES}

1. Ministério da Saúde. Boletim Epidemiológico - Aids e DST, Ano II - $n^{\circ} 1$ - até semana epidemiológica $26^{\text {a }}$ dezembro de 2013. Brasília: Ministério da Saúde; 2013 (Accessed 2014 May 15). Available at: http:// www.aids.gov.br/sites/default/files/anexos/publicacao/2013/55559/_p_ boletim_2013_internet_pdf_p__51315.pdf

2. Schiesari Jr A, Galisteu KJ, Cardoso LV, Schiesari VMB, da Cruz Furini AA, Rossit ARB, et al. Epidemiological patterns of AIDS in a reference center from Catanduva, São Paulo State, Brazil. Open J Med Microbiol 2012; 2:47-53.

3. Silva LCF, Santos EM, Silva Neto ALS, Miranda AE, Talhari S, Toledo LM. Pattern of HIV/AIDS infection in Manaus, State of Amazonas, between 1996 and 2000. Rev Soc Bras Med Trop 2009; 42:543-550.

4. Quinn TC. HIV epidemiology and the effects of antiviral therapy on long-term consequences. AIDS 2008; 22 (suppl III):7-12.

5. Demarchi IG, Cardoso DM, Aristides SMA, Moliterno RA, Silveira TGV, Cardoso RF, et al. Activity of antiretroviral drugs in human infections by opportunistic agents. Braz J Pharm Sci 2012; 48:171-185.

6. World Health Organization (WHO). HIV/AIDS. Geneva: WHO; 2014 (accessed 2014 May 15). Available at: http://www.who.int/hiv/en/
7. Brooks JT, Kaplan JE, Masur H. What's new in the 2009 US Guidelines for prevention and treatment of opportunistic infections among adults and adolescents with HIV. Top HIV Med 2009; 17:109-114.

8. Ministério da Saúde. Secretaria de Vigilância em Saúde. Departamento de DST, AIDS - Hepatites Virais. Brasília: Ministério da Saúde; 2014 (accessed 2014 June 18). Available at: http://www.aids.gov.br/pcdt/

9. Centers of Disease Control and Prevention (CDC). Opportunistic infections and their relationship to HIV/AIDS. Atlanta: CDC; 2014 (Accessed 2014 April 10). Available at: https://www.aids.gov/hivaids-basics/staying-healthy-with-hiv-aids/potential-related-healthproblems/opportunistic-infections/

10. Karp CL, Auwaerter PG. Coinfection with HIV and tropical infectious diseases. I. Protozoal pathogens. Clin Infect Dis 2007; 45:1208-1213.

11. Instituto Brasileiro de Geografia e Estatística (IBGE). Rio de Janeiro: IGBE; 2014 (accessed 2014 May 2). Available at: http:// cidades.ibge.gov.br/xtras/perfil.php?lang=\&codmun=354980\&sea $\mathrm{rch}=$ sao-paulo|sao-jose-do-rio-preto.

12. Nunes CLX, Gonçalves LA, Silva PT, Bina JC. Clinicalepidemiological characteristics of a group of HIV/AIDS infected women in Salvador-Bahia. Rev Soc Bras Med Trop 2004; 37:436-440.

13. Sistema de Informação de Agravos de Notificação (SINAN) Vigilância Epidemiológica. Programa Estadual DST/Aids-SP (VE-PE STD/AIDS - SP), 2010. Bepa 2011; 8:14-21.

14. Sharma A, Stephenson RB, White D, Sullivan PS. Acceptability and intended usage preferences for six HIV testing options among internet-using men who have sex with men. Springer Plus 2014; 3:109.

15. Gabriel R, Barbosa DA, Viana LAC. Perfil epidemiológico dos clientes com HIV/AIDS da Unidade Ambulatorial de Hospital Escola de Grande Porte - Município de São Paulo. Rev Latino-Am de Enfermagem 2005; 13:509-513.

16. Schuelter-Trevisol F, Pucci P, Justino AZ, Pucci N, Silva ACBD. Epidemiological profile of HIV patients in the southern region of Santa Catarina state in 2010. Epidemiol Serv Saude 2010; 22:87-94.

17. Bertoni RF, Bunn K, Silva J, Traebert J. Perfil demográfico e socio-econômico dos portadores de HIV/AIDS do ambulatório de controle de DST/AIDS de São José, SC. Arq Catarinenses Med 2010; 39:75-79.

18. Soares VYR, Lúcio Filho CEP, Carvalho LIM, Silva AM, Eulálio KD. Clinical and epidemiological analysis of patients with HIV/ AIDS admitted to a reference hospital in the northeast region of Brazil. Rev Inst Med trop São Paulo 2008; 50:327-332.

19. Ministério da Saúde. Secretaria de Vigilância em Saúde. Departamento de DST, AIDS e Hepatites virias. Adesão ao tratamento antirretroviral no Brasil: coletânea de estudos do projeto ATAR. Brasília: Ministério da Saúde; 2010 (accessed 2014 May 15). Available at: http://www.aids.gov.br/sites/default/files/ atar-web.pdf

20. Tapia C, Gonzales P, Pereira A, Pérez J, Noriega LM, Palavecino E. Antifungal susceptibility testing of Candida albicans isolates from AIDS patients with oropharyngeal and esophageal candidiasis. Experience with Etest ${ }^{\circledR}$. Rev Med Chile 2003; 131:515-519.

21. Lane HC. Pathogenesis of HIV infection: total CD4+ T-cell pool, immune activation, and inflammation. Top HIV Med 2010; 18:2-6.

22. Vlchkova-Lashkoska M, Kamberova S, Starova A, GolevaMishevska L, Tsatsa-Biljanovska N, Janevska V, et al. Cutaneous Cryptococcus laurentii infection in a human immunodeficiency virus-negative subject. J Eur Acad Dermatol Venereol 2004; 18:99-100. 
23. Pedro HSP, Pereira MIF, Goloni MRA, Pires FC, Oliveira RS, da Rocha MA. Mycobacterium tuberculosis in a HIV-1-infected population from Southeastern Brazil in the TARV era. Trop Med Int Health 2011; 16:67-73.

24. Furini AAC, Pedro HPS, Rodrigues JF, Montenegro LM, Machado $\mathrm{RL}$, Franco C, et al. Detection of Mycobacterium tuberculosis complex by nested polymerase chain reaction in pulmonary and extrapulmonary specimens. J Bras Pneumol 2013; 39:711-718.

25. World Health Organization (WHO). Tuberculosis and HIV. Geneva: WHO; 2012 (accessed 2014 March 18). Available at: http:// www.who.int/hiv/topics/tb/en/

26. Conde MB, Melo FAF, Marques ANC, Cardoso NC, Pinheiro VGF, Dalcin PTR, et al. III. Brazilian Thoracic Association Guidelines on Tuberculosis. J Bras Pneumol 2009; 35:1018-1048.

27. Victoria MB, Victoria FS, Torres KL, Kashima S, Covas DT, Malheiro A. Epidemiology of HIV/HCV coinfection in patients cared for at the Tropical Medicine Foundation of Amazonas. Braz J Infect Dis 2010; 14:135-140.
28. Mohammadi M, Talei G, Sheikhian A, Ebrahimzade F, Pournia Y, Ghasemi E, et al. Survey of both hepatitis B virus (HBsAg) and hepatitis $\mathrm{C}$ virus (HCV-Ab) coinfection among HIV positive patients. Virol J 2009; 18:202.

29. Braga WSM, Castilho MC, Santos ICV, Moura MAS, Segurado AC. Low prevalence of hepatitis B virus, hepatitis D virus and hepatitis $\mathrm{C}$ virus among patients with human immunodeficiency virus or acquired immunodeficiency syndrome in the Brazilian Amazon basin. Rev Soc Bras Med Trop 2006; 39:519-522.

30. Samuel MC, Doherty PM, Bulterys M, Jenison SA. Association between heroin use, needle sharing and tattoos received in prison with hepatitis $\mathrm{B}$ and $\mathrm{C}$ positivity among street-recruited injecting drug users in New Mexico, USA. Epidemiol Infect 2001; 127:475-484.

31. Raboni SM, Tuon FF, Beloto NCP, Demeneck H, Oliveira A, Largura $\mathrm{D}$, et al. Human immunodeficiency virus and hepatitis $\mathrm{C}$ virus/hepatitis B virus co-infection in southern Brazil: clinical and epidemiological evaluation. Braz J Infect Dis 2014; 18:664-668. 